\title{
Modified Total Intrinsic Rehabilitation Procedure for Ulnar Palsy
}

\author{
Venugopal Purushothaman ${ }^{1} \quad$ Jijo Joseph ${ }^{1}$ Sabari Girish Ambat ${ }^{1} \quad$ Krishnan Vinothkumar $^{1}$ \\ Ramaswami Venkataswami ${ }^{1}$ \\ 1Department of Plastic Surgery, Apollo First Med Hospital, \\ P.H. Road, Chennai, Tamil Nadu, India

\begin{abstract}
Address for correspondence Dr. Venugopal Purushothaman, MS, MCh, Department of Plastic Surgery, Apollo First Med Hospital, P.H. Road, Chennai 600010, Tamil Nadu, India (e-mail: v_purush2000@yahoo.com).
\end{abstract}

\begin{abstract}
Keywords

- claw hand

- metacarpophalangeal joint

- tendon transfer

- transverse metacarpal arch

- ulnar palsy

Tendon transfer for ulnar palsy has been an area of interest for many a stalwart in hand surgery, especially in southeast Asian countries, mainly because of the prevalence of Hansen's disease in these countries. Although the procedures look standardized, there are still many lacunae. Here in this article, we discuss about a surgical technique by which all the motor disabilities evolving due to ulnar nerve paralysis are addressed with three sets of tendon transfers performed in a single stage for: (1) key pinch restoration, (2) claw correction and adduction of fingers, and (3) claw correction and abduction of fingers.
\end{abstract}

\section{Introduction}

Ulnar nerve motors all muscles involved in fine intricate movements of the hand. When ulnar nerve is affected, it not only leads to claw deformity but the hand also becomes less efficient.

Paralysis of the intrinsic muscles results in impairment of fine intricate movements of the hand, precision grip, flattening of metacarpal arch, loss of power in key pinch, inability to cone or cup the hand, sensory loss along the ulnar border of hand, and volume loss in the entire hand. Overall precision and power in the hand are lost. ${ }^{1}$ An ulnar paralytic hand can make a tripod grip with the help of median nerve innervated lumbricals, but when power is needed, it collapses. So, to have power in the hand, ulnar innervated muscles ${ }^{2}$ are very important.

All the present transfers for ulnar nerve palsy mainly focus on correction of the claw (for metacarpophalangeal flexion and interphalangeal extension) and adduction of the four fingers except thumb. Certain procedures like
Palande ${ }^{3}$ technique of intrinsic reactivation also helps to regain the metacarpal arch, but none address restoration of key pinch mechanism and abduction of the fingers along with the regular claw correction. Our procedure corrects all the motor disabilities evolving due to ulnar nerve paralysis.

In our modified total intrinsic rehabilitation procedure, all the above-mentioned deficits are addressed with three sets of tendon transfers performed in a single stage for: (1) key pinch restoration, (2) claw correction and adduction of fingers, and (3) claw correction and abduction of fingers (-Fig. 1).

\section{Materials and Methods}

Six patients were operated in our institution from 2011 to 2016 with this technique of tendon transfer ( - Table $\mathbf{1}$ ). Four of them had ulnar claw hand and two had total claw. Average duration of paralysis was 19 months and mean age of the patients was 41 years. Two patients (patients no. 5 and 6 in -Table 1) were lost to follow-up. published online

December 30, 2020
DOI https://doi.org/

$10.1055 / \mathrm{s}-0040-1718857$ ISSN 0970-0358. (c) 2020. Association of Plastic Surgeons of India.

This is an open access article published by Thieme under the terms of the Creative Commons Attribution-NonDerivative-NonCommercial-License, permitting copying and reproduction so long as the original work is given appropriate credit. Contents may not be used for commercial purposes, or adapted, remixed, transformed or built upon. (https://creativecommons.org/licenses/by-nc-nd/4.0/)

Thieme Medical and Scientific Publishers Pvt. Ltd. A-12, 2nd Floor, Sector 2, Noida-201301 UP, India 
Functional outcome was assessed using Brand's criteria. ${ }^{4}$ The ability to cup and cone the hand was also assessed. Key pinch was assessed using Froment's sign.

The ability to perform coning of the hand was categorized into three grades (- Table 2, - Fig. 2). Cupping of the hand was also categorized into two grades-ability to cup and inability to cup (-Fig. 3).

\section{Surgical Technique}

The first transfer is for key pinch. In key pinch, when the thumb adducts, the index finger has to stabilize ${ }^{1}$ by abducting with the help of first dorsal interosseus (FDI), otherwise the index finger will collapse toward the ulnar side and there will be no power in key pinch. ${ }^{5}$ The extensor

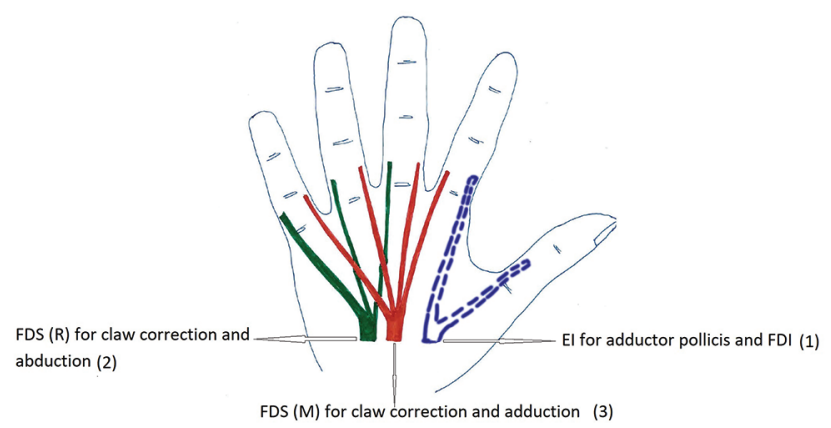

Fig. 1 Schematic diagram of tendon transfers. (1) 1st set of tendon transfers. (2) 2 nd set of tendon transfers. (3) 3rd set of tendon transfers. El, extensor indicis; FDI, first dorsal interosseus; FDS, flexor digitorum superficialis; $M$, middle finger; $R$, ring finger. indicis (EI) tendon is harvested by dorsal incision over the index finger metacarpophalangeal joint (MPJ) and retrieved proximally distal to extensor retinaculum, split into two slips and tunneled separately to thumb and index finger, and attached to the adductor pollicis (AP) and FDI. The motor can be the EI or one of the flexor digitorum superficialis (FDS) tendons. If EI is used as the motor, dorsal route is used to activate AP and FDI, and if FDS is used, it is routed across the palm to the respective insertions (-Fig. 4a, b). For insertion to FDI, midlateral incision is placed at the level of MPJ.

The second transfer is for claw correction, that is, metacarpophalangeal flexion and adduction of all four fingers. Just like how the abduction is important in opening the fingers, adduction is essential for grasping, with the latter being stronger $^{6}$ than the former. FDS (M) is harvested by distal palmar crease incision and retrieved proximally in the palm. The same is split into four slips, tunneled volar to transverse metacarpal ligament to all lateral bands, which are exposed by separate dorsal incisions, and attached to them like in Brand's ${ }^{7}$ procedure, that is, along the ulnar side of index finger and radial side of mid, ring and little fingers ( - Fig. 5).

The third transfer is for metacarpophalangeal flexion and abduction of middle, ring and little fingers. FDS (R) is harvested and retrieved as mentioned above. The same is split into three slips. First, FDS (R) is separated into two slips, and one of them used for hypothenar insertion. The other slip is further split into two slips, tunneled volar to transverse metacarpal ligament, and attached to the lateral bands of ring and middle finger on the ulnar side (-Fig. 6). For hypothenar insertion, midlateral incision is placed at the level of MPJ.

All the slips are looped around the tendon of insertion and sutured. First, we suture the FDS (M) slips. Next, FDS

Table 1 Preoperative patient details

\begin{tabular}{|l|l|l|l|l|l|l|l|}
\hline No. & Age/Sex & $\begin{array}{l}\text { Dominant/ } \\
\text { affected hand }\end{array}$ & $\begin{array}{l}\text { Type } \\
\text { of claw }\end{array}$ & $\begin{array}{l}\text { Duration } \\
\text { of paralysis }\end{array}$ & Cause & Low/High & Froment's sign \\
\hline 1. & $46 / \mathrm{M}$ & Right/right & Ulnar & 3 years & Hansen's disease & High with FDP M5 & Positive \\
\hline 2. & $14 / \mathrm{M}$ & Right/right & Total & 1 year & Supracondylar fracture & $\begin{array}{l}\text { High ulnar, high median, } \\
\text { long flexors recovered }\end{array}$ & Positive \\
\hline 3. & $25 / \mathrm{F}$ & Right/left & Ulnar & 1.5 years & $\begin{array}{l}\text { Ulnar nerve injury } \\
\text { during implant } \\
\text { removal for ORIF of } \\
\text { humerus fracture }\end{array}$ & $\begin{array}{l}\text { High ulnar with recovered } \\
\text { long flexors }\end{array}$ & Positive \\
\hline 4. & $67 / \mathrm{M}$ & Right/right & $\begin{array}{l}\text { Tardy } \\
\text { ulnar } \\
\text { palsy }\end{array}$ & 7 months & $\begin{array}{l}\text { Supracondylar fracture } \\
\text { High ulnar with recovered } \\
\text { long flexors }\end{array}$ & Positive \\
\hline 5. & $61 / \mathrm{M}$ & Right/right & Ulnar & 2 years & Hansen's disease & High with FDP M5 & Positive \\
\hline 6. & $34 / \mathrm{M}$ & Right/right & Total & 2 years & $\begin{array}{l}\text { Gunshot injury to right } \\
\text { shoulder }\end{array}$ & $\begin{array}{l}\text { High with long flexors } \\
\text { recovered }\end{array}$ & Positive \\
\hline
\end{tabular}

Abbreviations: FDP, flexor digitorum profundus; ORIF, open reduction internal fixation. 
Tables 2 Grading of coning of hand

\begin{tabular}{|l|l|}
\hline Grading & Appearance \\
\hline Excellent & All four fingers and thumb have pulp to pulp pinch \\
\hline Good & $\begin{array}{l}\text { Three fingers and thumb, except little finger, have } \\
\text { pulp to pulp pinch }\end{array}$ \\
\hline Poor & $\begin{array}{l}\text { Only one or two fingers have pulp to pulp contact } \\
\text { with thumb }\end{array}$ \\
\hline
\end{tabular}

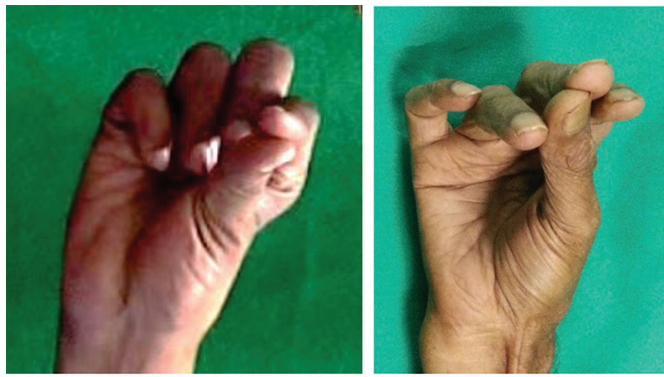

Poor

Fig. 2 Grading of coning of hand.

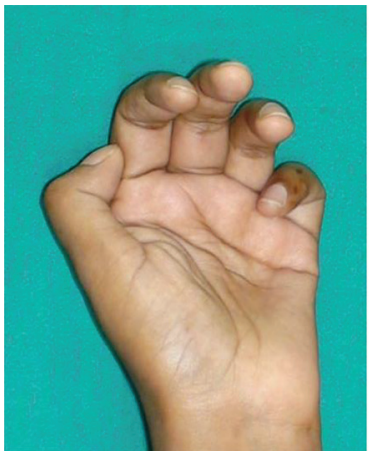

Unable to cup

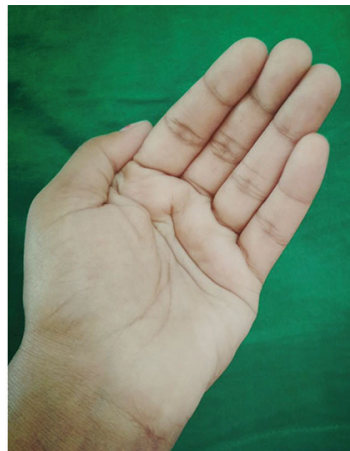

Able to cup
Fig. 3 Grading of cupping of hand.
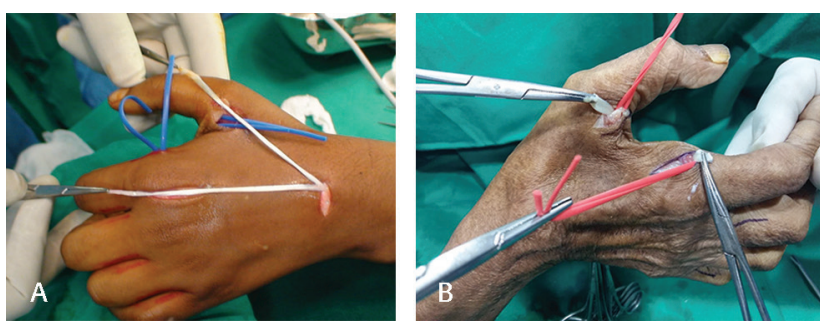

Fig. 4 1st set of tendon transfer. Extensor indicis (EI)/flexor digitorum superficialis (FDS) to adductor pollicis (AP) + first dorsal interosseus (FDI). (a) El to AP + FDI. (b) FDS to AP + FDI.

(R) slips are sutured. Finally, while suturing EI to FDI and AP, the thumb is kept midway between full abduction and adduction. At the end of the procedure, the hand in resting position should have normal finger cascade along with thumb index opposition ( - Fig. 7 ).

The hand is immobilized with wrist in neutral, MPJ in 70 to 80 degree flexion, interphalangeal joint (IPJ) straight with a dorsal and volar slab, and thumb midway between full abduction and adduction. Plaster of Paris slab is retained for 3 weeks and physiotherapy started. During the 4th week, the patient is advised to do active wrist flexion which, in turn, will lead to passive extension of all fingers; and active extension of the wrist which, in turn, will lead to passive flexion of all fingers. From the 5th to the 8th week, the patient is encouraged to actively extend and abduct all fingers and then to cone and cup the hand. Thereafter, they are encouraged to perform active flexion

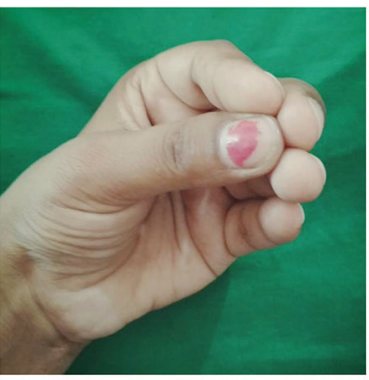

Good

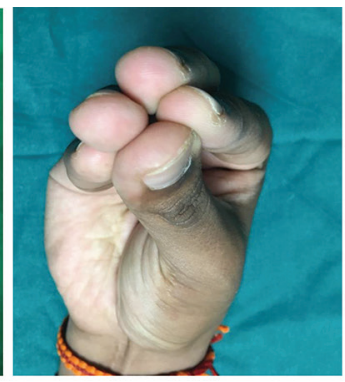

Excellent

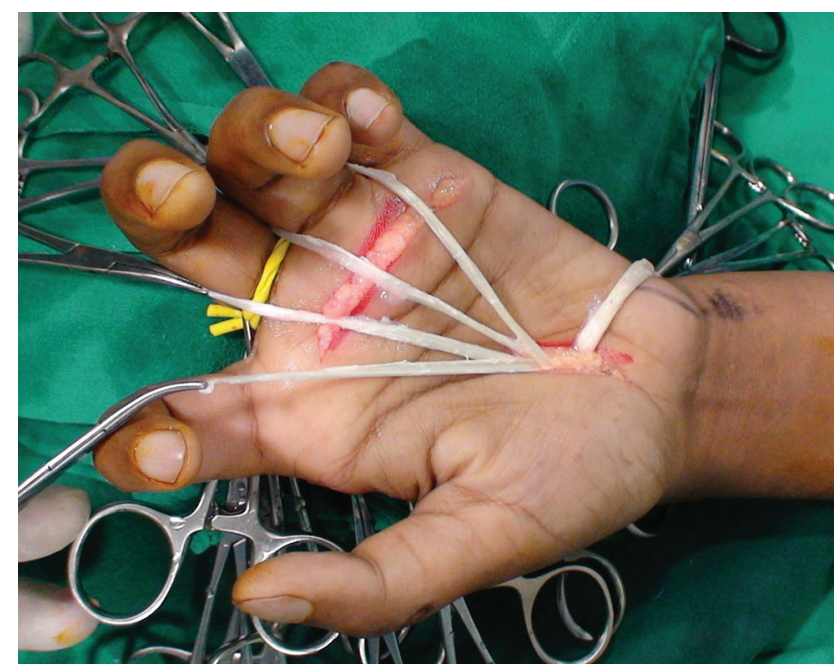

Fig. 5 2nd set of tendon transfer. Flexor digitorum superficialis (FDS) (M) to Ulnar lateral band of index finger and radial lateral bands of middle, ring and little fingers.

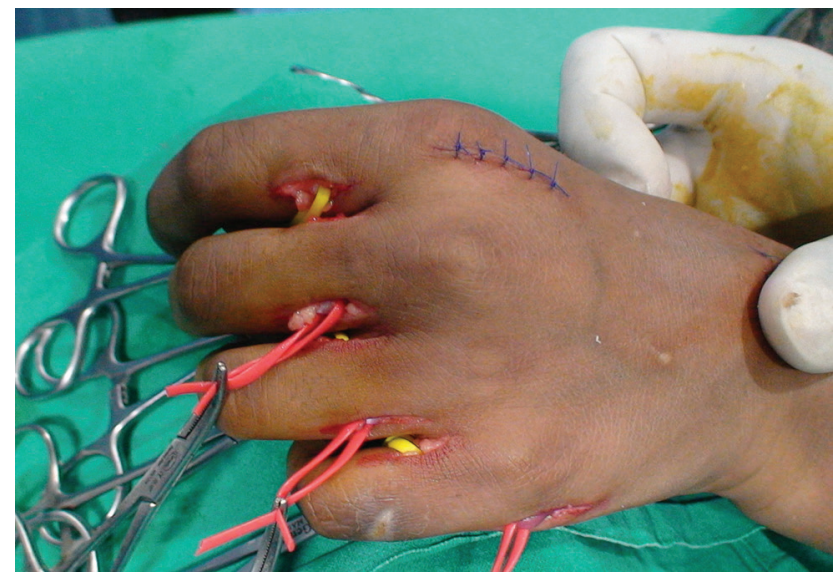

Fig. 6 3rd set of tendon transfer. FDS (R) to Ulnar lateral bands of middle, ring fingers and hypothenar insertion (red tags). 


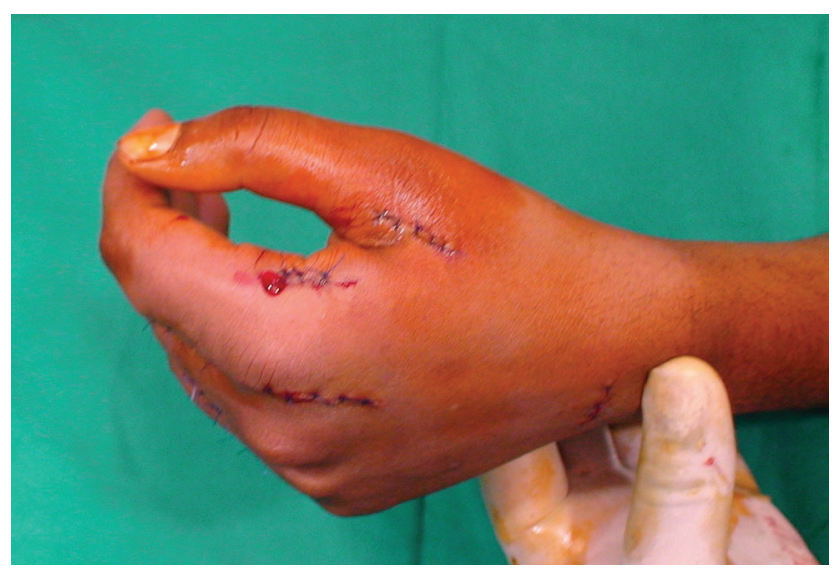

and adduction of all fingers together. Complete flexion of fingers to make a fist and passive flexion of fingers is done only after the 8 th week.

\section{Results}

All hands were analyzed using Brand's criteria ${ }^{4}$ (- Tables 3-5). A comparison has been made between preoperative and 3-year postoperative presentation.

Cupping and coning of the hands were also assessed, based on the criteria mentioned above ( - Tables 6 and 7;

\section{-Figs. 8-10, Video 1)}

Fig. 7 Restoration of normal finger cascade at the end of procedure.

Tables 3 Open hand analysis

\begin{tabular}{|l|l|l|l|l|l|l|l|l|l|}
\hline \multirow{2}{*}{} & \multirow{2}{*}{ Type of claw } & \multicolumn{9}{|c|}{ Open hand analysis } \\
\cline { 3 - 10 } & & \multicolumn{2}{|c|}{ Index } & \multicolumn{2}{c|}{ Middle } & \multicolumn{2}{c|}{ Ring } & \multicolumn{2}{c|}{ Little } \\
\cline { 3 - 10 } & Preop & Postop & Preop & Postop & Preop & Postop & Preop & Postop \\
\hline 1 & Ulnar & & & & & Fair & Excellent & Poor & Excellent \\
\hline 2 & Total & Poor & Excellent & Poor & Excellent & Poor & Excellent & Poor & Excellent \\
\hline 3 & Ulnar & & & & & Fair & Excellent & Poor & Excellent \\
\hline 4 & Ulnar & & & & & Fair & Excellent & Fair & Excellent \\
\hline
\end{tabular}

Tables 4 Closed fist analysis and analysis of sequence of flexion

\begin{tabular}{|l|l|l|l|l|}
\hline \multirow{2}{*}{ S.L. No. } & \multicolumn{2}{|c|}{ Closed fist analysis } & \multicolumn{2}{c|}{ Sequence of flexion } \\
\cline { 2 - 5 } & Preop & Postop & Preop & Postop \\
\hline 1 & Fair & Excellent & Poor & Excellent \\
\hline 2 & Fair & Good & Fair & Excellent \\
\hline 3 & Good & Excellent & Good & Excellent \\
\hline 4 & Poor & Poor & Fair & Good \\
\hline
\end{tabular}

Tables 5 Assessment of lumbrical position

\begin{tabular}{|l|l|l|l|l|l|l|l|l|l|}
\hline \multirow{2}{*}{} & \multirow{2}{*}{} & \multirow{2}{*}{ Type of claw } & \multicolumn{9}{|c|}{ Assessment of lumbrical position } \\
\cline { 3 - 10 } & & \multicolumn{2}{|c|}{ Index } & \multicolumn{2}{c|}{ Middle } & \multicolumn{3}{c|}{ Ring } & \multicolumn{2}{c|}{ Little } \\
\cline { 3 - 10 } & Pre op & Postop & Pre op & Postop & Pre op & Postop & Pre op & Postop \\
\hline 1 & Ulnar & & & & & Fair & Excellent & Good & Excellent \\
\hline 2 & Total & Good & Excellent & Good & Excellent & Fair & Excellent & Fair & Excellent \\
\hline 3 & Ulnar & & & & & Fair & Excellent & Poor & Excellent \\
\hline 4 & Ulnar & & & & & Good & Excellent & Fair & Excellent \\
\hline
\end{tabular}

Tables 6 Assessment of coning of hand

\begin{tabular}{|l|l|l|}
\hline S.L. & Preop & Postop \\
\hline 1 & Poor & Good \\
\hline 2 & Poor & Excellent \\
\hline 3 & Poor & Good \\
\hline 4 & Poor & Good \\
\hline
\end{tabular}

Tables 7 Assessment of cupping of hand

\begin{tabular}{|l|l|l|}
\hline $\begin{array}{l}\text { S.L. } \\
\text { No. }\end{array}$ & Preop & Postop \\
\hline 1 & Unable to cup & Able to cup \\
\hline 2 & Unable to cup & Able to cup \\
\hline 3 & Unable to cup & Able to cup \\
\hline 4 & Unable to cup & Able to cup \\
\hline
\end{tabular}



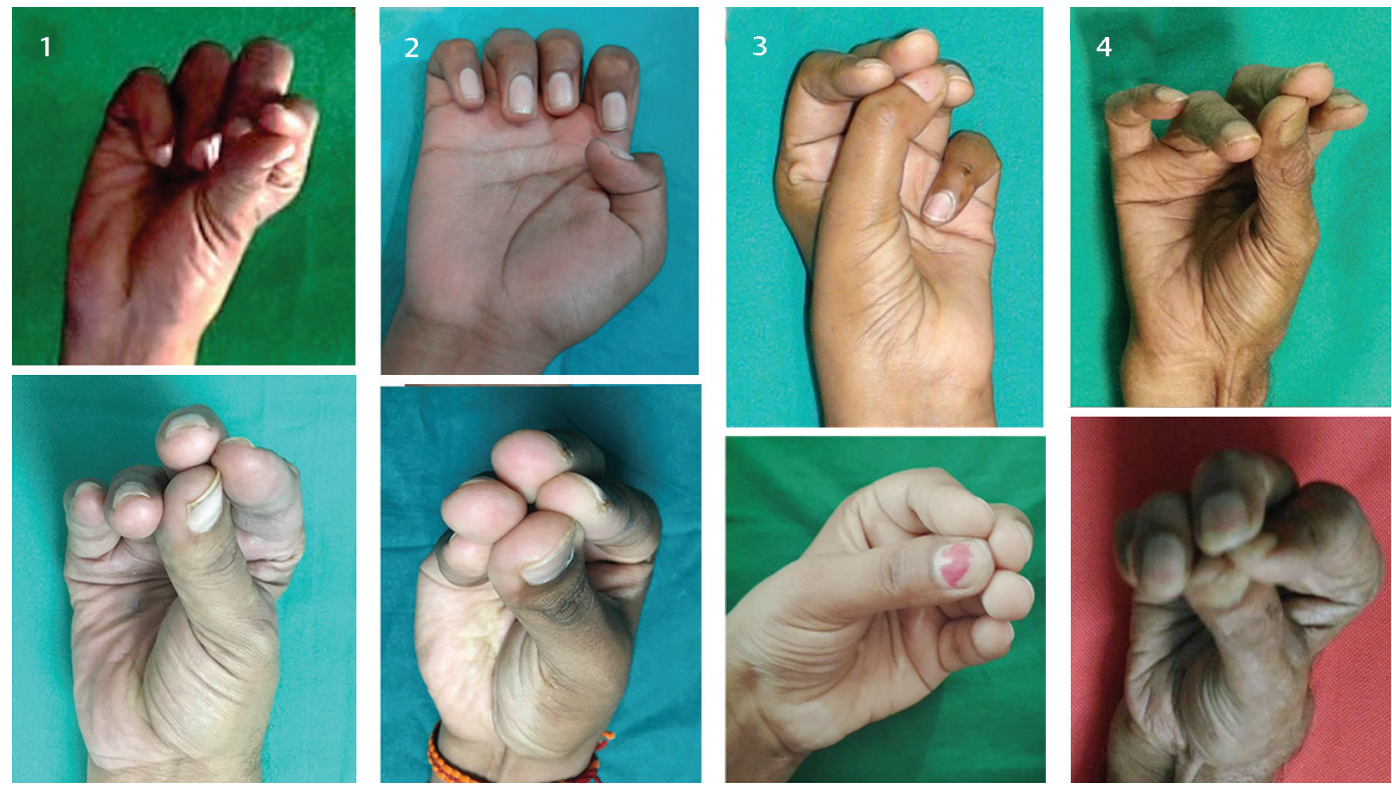

Fig. 8 Preoperative and postoperative images of coning of hand of all the four patients.

\section{Video 1}

Patient no. 3 holding water in her palm by cupping. Online content including video sequences viewable at: https://www.thieme-connect.com/products/ejournals/ html/10.1055/s-0040-1718857.

Froment's sign became negative for all the patients (-Fig. 11)

Significant improvement was noted in all the parameters studied. The one drawback noted was inadequate adduction of little finger when compared with other fingers. One patient aged 67 years was not able to make a complete fist.

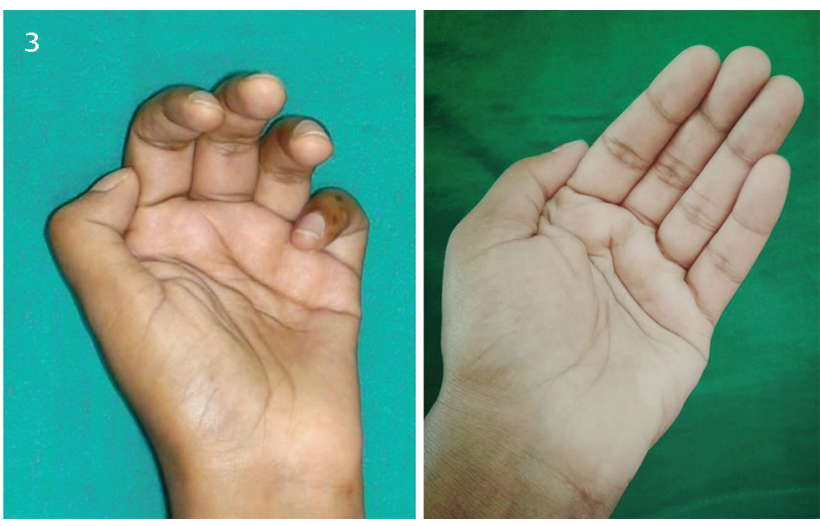

Fig. 9 Preoperative and postoperative image of cupping of hand of patient no. 3.

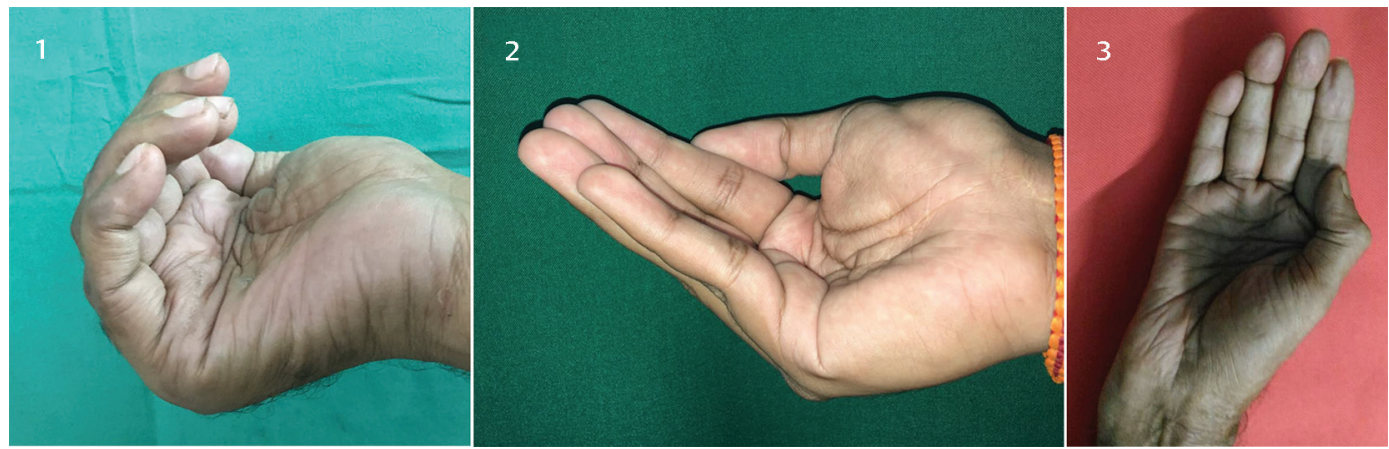

Fig. 10 Postoperative images of cupping of hand of patient nos. 1, 2 and 4.
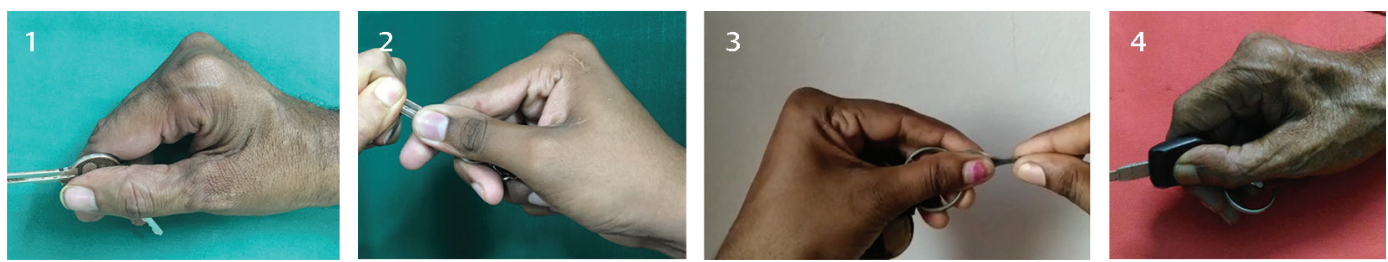

Fig. 11 Disappearance of Froment's sign postoperatively. 


\section{Case Study (Patient no.3)}

A 25-year-old, right-handed female patient, housewife, presented with ulnar claw deformity of left hand for a duration of 18 months following supracondylar fracture. She had undergone anterior transposition of ulnar nerve 6 months after the injury in spite of which the symptoms did not improve. The strength of flexor digitorum profundus (FDP) of middle, ring and little fingers was M4 at the time of tendon transfer. The preoperative and postoperative images at 3 years of follow-up are shown ( - Fig. 12a, b, c, d, e; Videos 1 and 2 [online only])

\section{Video 2}

Patient trying to pull the key with her right hand, showing that there is no Froment's sign or collapse of the thumb. Online content including video sequences viewable at: https://www.thieme-connect.com/products/ejournals/ html/ 10.1055/s-0040-1718857.

\section{Discussion}

In sublimis transfer of Stiles and Bunnell, ${ }^{7,8}$ sublimis tendon to each finger was harvested and connected to both lateral bands, which led to the development of intrinsic plus deformity. This was corrected by Littler's ${ }^{9}$ (modified Stiles-Bunnell) operation in which only one or two sublimis tendons were harvested, split into several strands, and transferred to the radial lateral band of index, middle, ring and little fingers. Brand ${ }^{7}$ and Fritchi ${ }^{8}$ used the ulnar lateral band of index finger instead of the radial lateral band. These transfers were helpful in flexing the MPJ, extending the proximal interphalangeal joint (PIPJ), and also aided in adducting the fingers.

Zancolli ${ }^{10,11}$ described looping the tendon slips around common interosseous tendon in 2, 3, 4 web space as direct interosseous activation. This helped in the abduction of fingers. ${ }^{11}$ By his total intrinsic reactivation, Palande ${ }^{3}$ achieved reversal of metacarpal arch and convergence of fingers but neither did he address key pinch nor the abduction of fingers. Bunnell ${ }^{3}$ also observed that metacarpal arch is essential for strength, and cupping of the hand and the fingers converging in flexion.

In key pinch, the resistance offered by index finger is increased by stacking up of other fingers behind it. ${ }^{1}$ This is made possible by restoration of adduction of the latter. Previous transfers for restoration of key pinch were done either to AP or to FDI or to both. ${ }^{12}$ Omer $^{13}$ described transfer to both with the single tendon.

Modified total intrinsic rehabilitation procedure not only corrects the claw deformity but also helps in restoring key pinch, cupping and coning of hand. With this, all the intrinsic deformities are corrected through single surgery which none of the current procedures address. Patients are able to cup their hand to take water and eat food, which are important in the Indian population.

\section{Preoperative images}

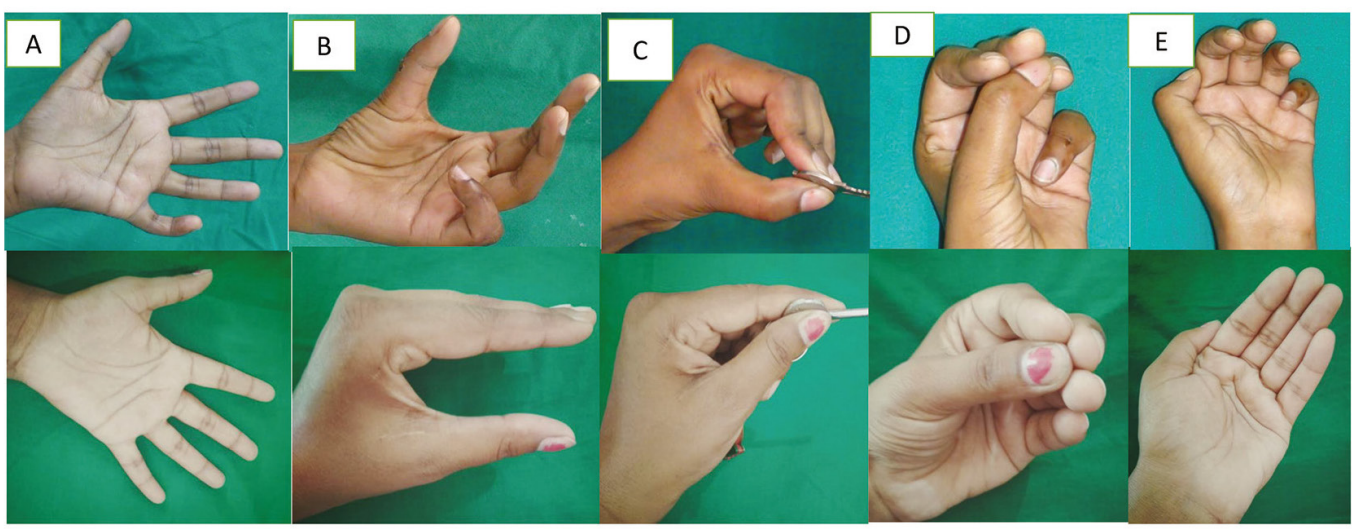

\section{Postoperative images}

Fig. 12 (a) Open hand assessment-preoperative and postoperative. (b) Assessment of lumbrical position-preoperative and postoperative. (c) Assessment of key pinch-preoperative image showing z-deformity and postoperative image showing correction of z-deformity. (d) Coning of hand-preoperative and postoperative. (e) Cupping of hand-preoperative and postoperative. 


\section{Note}

Presented in National Conference of Plastic Surgeons of India (APSICON) in 2018 and won the Dr. Ashok Raj Koul best innovation award.

\section{Conflicts of Interest}

None declared.

\section{References}

1. Smith P, Lister's The Hand: Diagnosis and Indications. 4th ed. Edinburgh: Churchill Livingstone; 2002: 146

2. Smith P, Lister's The Hand: Diagnosis and Indications. 4th ed. Edinburgh: Churchill Livingstone; 2002: 148

3. Palande DD. Correction of intrinsic-minus hands associated with reversal of the transverse metacarpal arch. J Bone Joint Surg Am 1983;65(4):514-521

4. Brand PW. Paralytic claw hand; with special reference to paralysis in leprosy and treatment by the sublimis transfer of Stiles and Bunnell. J Bone Joint Surg Br 1958;40-B(4):618-632

5. Green DP, Pederson WC, Hotchkiss RN, Green's Operative Hand Surgery. 4th ed. Philadelphia: Churchill Livingstone; 1998: 1127
6. Pataky TC, Latash ML, Zatsiorsky VM. Multifinger ab- and adduction strength and coordination. J Hand Ther 2008; 21(4):377-385

7. Brand PW. Tendon grafting: illustrated by a new operation for intrinsic paralysis of the fingers. J Bone Joint Surg $\mathrm{Br}$ 1961;43(3):444-453

8. Fritschi, Ernest P. The restoration of finger function. In: Reconstructive Surgery in Leprosy. Bristol (UK): John Wright \& Sons; 1971: 42-65

9. Littler JW. Tendon transfers and arthrodeses in combined median and ulnar nerve paralysis. J Bone Joint Surg Am 1949;31A(2):225-234

10. Zancolli EA, Structural and Dynamic Bases of Hand Surgery. 2nd ed. Philadelphia: JB Lippincott; 1979: 159-206

11. Peter CN, Richard JW. Plastic surgery. 3rd edition. Philadelphia. Saunders; 2012.767

12. Wolfe SW, Pederson WC, Hotchkiss RN, Kozin HS, Green's Operative Hand Surgery. 6th ed. Philadelphia: Churchill Livingstone; 2011: 1127

13. Green DP, Pederson WC, Hotchkiss RN, Green's Operative Hand Surgery. 4 th ed. Philadelphia: Churchill Livingstone; 1999. 1536 